УДК 343.988:343.34:004.056

https://doi.org/10.24866/1813-3274/2021-2/113-122

Д. В. Жмуров ${ }^{1}$, Байкальский государственный университет экономики и права, г. Иркутск, Россия

E-mail: zdevraz@ya.ru

\title{
КИБЕРВИКТИМНОСТЬ КАК НОВАЯ КАТЕГОРИЯ ВИКТИМОЛОГИИ ПОСТМОДЕРНА
}

Аннотачия. Статья посвящена новому явлению, определяемому как кибервиктимность. В работе выявлены её специфические характеристики, сформулирована дефиниция этого термина. Под кибервиктимностью предлагается понимать способность индивида быть жертвой компьютерных преступлений в силу субъективной или объективной уязвимости. Автор отмечает, что указанное явление выходит за пределы классической виктимологии и нуждается в серьёзном научном осмыслении. В настоящей статье дан краткий анализ некоторых проблем, имеющихся в содержательном поле кибервиктимности, рассмотрен вопрос соотношения терминов «кибержертва» и «субъект кибевиктимизации», перечислены виды таких субъектов.

Ключевые слова: кибервиктимность, кибервиктимология, интернет-потерпевший, жертвы цифровых преступлений, кибержертва, субъект кибервиктимизации, цифровая криминология, пострадавший в интернет-среде, кибервиктимизация, факторы кибервиктимизации, криминология цифрового мира.

\footnotetext{
1 Дмитрий Витальевич Жмуров, кандидат юридических наук, доцент кафедры уголовного права и криминологии Байкальского государственного университета экономики и права, руководитель проекта «Национальная энциклопедическая служба России», г. Иркутск, Россия.

Для циитирования: Жмуров Д. В. Кибервиктимность как новая категория виктимологии постмодерна // Азиатско-Тихоокеанский регион: экономика, политика, право. 2021. №. 2. С. 113-122. DOI https://doi.org/10.24866/1813-3274/2021-2/113-122.
}

(C) Жмуров Д. В., 2021 
Dmitriy V. Zhmurov ${ }^{1}$, Baikal State University, Irkutsk, Russia

E-mail: zdevraz@ya.ru

\section{CYBER-VICTIMHOOD AS A NEW CATEGORY OF POSTMODERN VICTIMOLOGY}

Abstract. The article is devoted to a new phenomenon, defined as cyber-victimhood. The paper reveals its specific characteristics and suggests a definition of this term. Cybervictimhood is understood as the ability of an individual to be a victim of computer crimes due to subjective or objective vulnerability. The author notes that this phenomenon goes beyond classical victimology and needs serious scientific reflection. This article provides a brief analysis of the problems in the content field of cyber-victimhood, considers the question of the relationship between the terms «cyber-victim» and «subject of cybervictimization», lists the types of such subjects.

Keywords: cyber-victimhood, cyber-victimology, internet victim, victims of digital crimes, cyber-victim, subject of cyber-victimization, digital criminology, victim in the internet environment, cyber-victimization, factors of cyber-victimization, criminology of the digital world.

Считается, что начало виктимологии положила публикация немецкого криминолога Г. Гентига «Замечания по интеракции между преступником и жертвой» (1941). Он писал о диалогической природе преступного поведения, где обе стороны - субъекты взаимодополняющего партнёрства, в котором проявляется «...негласное взаимопонимание преступника и жертвы... имеет место интеракция, взаимодействие и обмен элементами причинности». На тот момент казалось, что это действительно так.

Но время меняет наши представления об окружающем мире и процессах, происходящих в нём. Коренные перемены в миропонимании неизбежны, а слом и обновление научных парадигм человечество переживало уже не раз. Подобно тому как пространственно-временная теория Эйнштейна перевернула классические ньютоновские представления о природе, революционные перемены не обходят стороной и гуманитарные науки. Вероятно, что в современных условиях виктимологии

\footnotetext{
${ }^{1}$ Dmitriy Vitalievich Zhmurov, Candidate of Law, Associate Professor of the Department of Criminal Law and Criminology of the Baikal State University of Economics and Law; Coordinator of Project «National Encyclopedic Service of Russia», Irkutsk, Russia.

For citing: Zhmurov D. V. Cyber-victimhood as a new category of postmodern victimology // PACIFIC RIM: Economics, Politics, Law. 2021. No 2. P. 113-122. DOI https://doi.org/10.24866/1813-3274/20212/113-122.
} 
постмодерна мы подошли к пределу, выходящему за грани установленной Гентигом максимы. Киберпреступность и виртуализация отношений между жертвой и злоумышленником, появление опосредующих элементов в этой цепи взаимодействия, преступные покушения и взломы IOT, т. е. интернета вещей - всё это говорит об изменении базовых начал коммуникации между сторонами преступного акта. В некоторых случаях «классическая механика» виктимологии, описанная немецким учёным, не работает, поскольку интеракции в привычном смысле не происходит. Между современной и старой преступностью существует не только антагонизм, но и существенная разница в методах воздействия на потерпевших. Сегодня используются незнакомые ранее приёмы, принципиально новые подходы к поиску, отбору и контакту с потенциальными жертвами.

Постараемся подробно сформулировать упомянутые особенности современной виктимологии.

Во-первых, отмечаются существенные изменения в укладе взаимодействия сторон криминального акта. Они всё более выходят за пределы отношений «хищник - жертва». Одной из важных идей криминального причинения в киберпространстве становится «философия умиротворения»- отказ от прямого воздействия на потерпевшего, стремление максимально замаскировать свои действия, если это возможно. Часто жертвы даже не подозревают, что им причиняется урон. Это пример избегания открытой конфронтации и явной агрессии со стороны преступников новой формации. Подобная стратегия гарантирует им безопасность, исключает мотивацию возмездия у пострадавшей стороны. Если использовать биологическую терминологию, то здесь уместно сравнение не с хищинчеством, а с комменсализмом, при котором один из партнёров (комменсал) возлагает на другого (хозяина) регуляцию своих отношений с внешней средой, извлекая из этого выгоду. Например, криптоджекинг ${ }^{1}$, куки-стаффинг ${ }^{2}$, трояны в сфере партнёрского интернет-

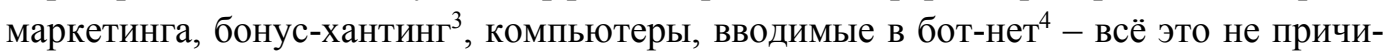
няет потерпевшим какого-либо ощутимого вреда, позволяя правонарушителям иметь доход. Иногда отношения сторон уголовного деликта напоминают симбио-

\footnotetext{
${ }^{1}$ Криптоджекинг - это когда компьютер или смартфон жертвы используются без её разрешения, причем не для кражи данных, а для того, чтобы киберпреступники могли «добывать» (майнить) криптовалюты без использования своих собственных ресурсов.

2 Куки-стаффинг - мошеннический инструмент в сфере партнерского интернет-маркетинга, означающий перенаправление пользователя без его ведома по партнёрской ссылке какого-либо сайта и начисление комиссии перенаправившему лицу.

${ }^{3}$ Бонус-хантинг - различные формы присвоения бонусов, кэшбэков, призовых баллов и проч.

${ }^{4}$ Бот-нет (ботнет) - компьютерная сеть, состоящая из некоторого количества хостов с запущенными ботами - автономным программным обеспечением. Чаще всего бот в составе ботнета является программой, скрытно устанавливаемой на устройство жертвы и позволяющей злоумышленнику выполнять некие действия с использованием ресурсов заражённого компьютера. Обычно используются для нелегальной или неодобряемой деятельности - рассылки спама, перебора паролей на удалённой системе, атак на отказ в обслуживании (DoS- и DDoS-атаки).
} 
тические, т. е. обоюдовыгодные: преступники взламывают платные программы и публикуют их с внедрённым вредоносным кодом. Этот софт скачивают пользователи, заведомо зная об опасности, но рассчитывая на минимальные негативные последствия или их отсутствие. Не будь такого «молчаливого соглашения», когда одни взламывают, а другие - пользуются, многие вирусы просто не смогли бы распространяться. Известны случаи, когда вредоносное ПО даже выполняет полезные функции (оптимизирует работу компьютера, блокирует рекламу, ищет вирусы, чистит диск и проч.). Например, один из видов фрода, т. н. мошеннические тулбары (toolbar) - это браузерные расширения в верхней строке с дополнительным функционалом (прогноз погоды, сведения о безопасности сайта, индикатор почтового ящика и т. д.). Поскольку тулбар имеет доступ к загружаемым веб-страницам, он может «вмешиваться» в их работу. Поэтому он вполне способен перенаправить посетителя на другой адрес - причём это будет тот же самый сайт, что и выбрал пользователь, только с партнёрской меткой от создателя тулбара или того, кто ему заплатил [7]. В конечном счёте мошенник получит вознаграждение за приведённого клиента, а потерпевший зайдет на нужный сайт и сделает необходимые покупки.

Во-вторых, наблюдается размывание некоторых ключевых понятий виктимологии, например, субъекта индивидуальной виктимизации, т. е. физического лица, непосредственной жертвы преступления. Дело в том, что среди тех, кого атакуют в сетевом пространстве, присутствуют как традиционные жертвы, подпадающие под это определение (люди, юридические лица, государства), так и не совсем классические фигуры (автономные бытовые приборы IOT, веб-ресурсы, информационные роботы, сетевое оборудование и серверы). Это наглядно продемонстрировал специалист компании Avast M. Хрон, взломавший в 2020 г. «умную» кофеварку, перенаправив мощности её процессора на добычу криптовалюты [5]. Конечно, с ортодоксальных позиций определить в этой ситуации жертву не трудно. Можно объявить ею собственника кофемашины. Хотя делать это желательно с пониманием того, что реального вреда ему причинено не было. Но как поступать с пострадавшими «неодушевленными системами», у которых нет хозяина и которые никому не принадлежат? Например, таков целый кластер интеллектуальных активов, самоорганизующихся структур, именуемых FLOSS, или FOSS (свободное программное обеспечение с открытыми исходными кодами). К нему относится ядро Linux, и оно «никому не принадлежит. Точнее, можно сказать, что оно принадлежит сообществу программистов. На бесплатной основе каждый желающий может вносить свои изменения, которые в дальнейшем принимаются сообществом» [9].

В-третьих, учёные-виктимологи приписывают контакту преступника и жертвы некоторую психологическую согласованность. Считается, что жертва выбирается «не случайно, а по точным критериям и характеристикам» [3]. Преступник и пострадавший психологически подходят друг другу, по выражению Г. Гентига, как 
«замок и ключ». Киберпреступность своим существованием, напротив, ставит под сомнение данное положение. Во многом она основана на случайном, рандомизированном выборе жертв. Более того, никакого взаимодействия между акторами криминального процесса может и не быть, кроме опосредованного, косвенного контакта через установленную вредоносную программу. Приведённый выше пример про кофемашину также опровергает факт психологической соприкосновенности между IT-преступником и предметом его атаки.

В-четвёртых, классическая виктимология одной из важных переменных называет действие виктимогенных личностных и виктимогенных cumyационных факторов. Первое - это уязвимости индивида, второе - условия внешней среды, детерминирующие поведение потерпевшего. В обоих случаях жертва активна, именно она стимулирует преступное поведение своими уязвимостями, либо ситуационной деятельностью. В постмодернисткой виктимологии детерминациионные связи между преступником и жертвой усложняются и не исчерпываются причинностью или условиями взаимодействия этих сторон. Например, личностные и ситуационные факторы виктимности не будут иметь значения при совершении акта кибертерроризма, когда дестабилизируется система энергоснабжения. Эти действия, в свою очередь, могут привести к локдауну на критически важных узлах (транспорте, здравоохранении и проч.). А пострадавшие при этом люди (например, больные на операционном столе, пассажиры автоматических транспортных средств) абсолютно не будут демонстрировать ни личностных, ни ситуационных факторов виктимности.

В-пятых, отмечаются совершенно нетипические случаи возникновения виктимных сообществ, представляющих массовые объединения потенциальных жертв, каждая из которых надеется таковой не стать («эпименические ульи» или «консорциумы жертв»). Например, так происходит в хайп-проектах, которые фактически представляют собой финансовые пирамиды с тысячами участников. Каждый из них надеется заработать и не опоздать вывести средства до того, как всё окончательно рухнет. Часто организаторы этих пирамид даже не скрывают истинных целей проекта, а инвесторы - «потенциальные жертвы» понимают, что их доходы складываются из взносов вновь прибывших участников. Поэтому им ничего не остается, кроме того, как привлекать новичков. Получается так, что жертвы сами ищут новых жертв. Как только поток неофитов иссякнет, они станут фактическими потерпевшими, рассчитывая, конечно, что до этого не дойдет. Таких «союзов жертв», где каждый надеется не оказаться последним, в интернете предостаточно.

Всё сказанное свидетельствует о формировании обновленного виктимологического дискурса. Он не столь однозначен и зауряден, в отличие от классического варианта. В связи с этим представляется уместной одна аналогия. Если, по выражению немецкого философа Макса Хоркхаймера, двадцатый век подарил нам новый антро- 
пологический тип человека, а именно авторитарную личность, можно утверждать, что двадцать первому веку мы обязаны появлением личности виртуальной жертвь и нового формирующего её типа виктимности. При этом наблюдается некоторое смещение смысловых акцентов: термины «пострадавший» и «потерпевший» частично утрачивают свою семантическую окраску. Они не всегда обозначают тот смысловой контекст, который изначально был заложен в них производящим словом, а именно лексами «страдать» и «терпеть». То есть кибержертва не всегда «страдающая» или «претерпевающая». Уже упоминалось, что в ряде случаев наносимый вред минимален, нераспознаваем, неочевиден даже для самого потерпевшего.

Кибервиктимность представляет малоисследованную научную категорию и несомненно вызывает интерес учёных. Её изучение всецело отвечает требованиям виктимной безопасности как системы обеспечения защищённости личности и общества [4], в данном контексте - речь о безопасности в кибернетическом пространстве.

Термин «кибервиктимность» учёными используется, хотя, к сожалению, авторы не всегда предлагают его определение (E. A. Антонян, E. Н. Клещина, 2019; Д. Е. Никешин, 2021). А. Р. Дроздикова-Зарипова, Н. Н. Калацкая и коллеги под кибервиктимностью понимают «системное и динамичное свойство личности, проявляющееся в форме ее сочиального, биологического, психологического и морального деформационного отклонения, закрепленного в неосторожных, импульсивных, провоцирующих формах поведения, не соответствующего нормам безопасности и обусловливающего потенцииальную или реальную предрасположенность субъекта становиться жертвой преступлений в глобальной сети Интернет» [11]. В. А. Плешаков и Т. В. Склярова обозначают кибервиктимность как вероятность человека стать жертвой киберсоцииализаџии [10]. С авторской точки зрения, кибервиктимность можно обозначить как способность индивида быть жертвой компьютерных преступлений в силу субъективной или объективной уязвимости. Индивид - в данном случае - толкуется максимально расширительно, как биологический, социальный, технический организм с присущей ему степенью автономизации.

Существует несколько подходов к рассмотрению виктимности, и они вполне применимы к её кибернетической форме. Немалая часть исследователей под виктимностью понимают системное свойство, связанное с предрасположенностью становиться жертвой (О. О. Андроникова, Т. В. Варчук, Д. В. Ривман, В. Я. Рыбальская, А. В. Туляков, Л. В. Франк). Другие рассматривают виктимность как следствие социильного воздействия или дефицитарности механизма социогенеза (Г. М. Андреева, А. В. Мудрик, Е. В. Руденский, А. Б. Серых) [2].

Памятуя о сложности и многокомпонентности процессов виртуальной виктимизации, целесообразно ввести переменную субъекта кибервиктимизации. По своему содержанию этот термин несколько отличен от понятия кибержертвы. Последняя это лицо, признанное потерпевшим от преступления в цифровой среде, а субъект ки- 
бервиктимизации - это актор виртуального пространства, которому причинен материальный, технический, организационный и иной ущерб. К таким субъектам можно отнести: а) компьютеры, серверы и сетевое оборудование; б) веб-ресурсы; в) людей; г) банкоматы и pos-терминалы; д) мобильные устройства; е) IOT [1]. Специалисты по сетевой безопасности Positive Technologies указали на 15 наиболее часто встречающихся категорий субъектов кибервиктимизации в зависимости от принадлежности к той или иной сфере общественной жизни. Среди них:

- финансовая отрасль;

- государственные учреждения;

- медицинские учреждения;

- наука и образование;

- оборонные предприятия;

- промышленные компании;

- онлайн сервисы;

- сфера услуг;

- транспорт;

- ІТ-компании;

- торговля;

- частные лица;

- телекоммуникационные компании;

- блокчейн-проекты;

- другие сферы.

Если говорить об одушевлённых кибержертвах и их характеристиках, то, по данным исследований, чаще всего интернет-рискам подвергаются люди в возрасте 19-35 лет (миллениалы) - 88\%, чуть меньше пользователи 36-50 лет (поколение X) - 84\% и 51-73 года (бумеры) - 76\%. Реже всего (73\%) интернет-угрозам подвержены подростки до 18 лет (зумеры) [12]. Следовательно, виктимологическому риску подвержены более молодые слои населения в силу их большей приверженности к современным технологиям [8].

При этом отмечается, что респонденты в РФ традиционно сталкиваются с поведенческими рисками в сети - $61 \%$ против среднемирового показателя $45 \%$. 44\% опрошенных жителей России подверглись грубому обращению, 43\% - онлайндомогательствам, $29 \%$ - троллингу, $53 \%$ - навязчивому поведению с онлайнмошенничеством и нежелательным контактам (44\%) [12]. Вероятно, эти показатели являются весьма приблизительными, поскольку унифицированных критериев оценки кибервиктимности пока не выработано.

Таким образом, кибервиктимность представляет собой самостоятельную и немаловажную проблему. Она явно выходит за привычные виктимологические рам- 
ки, предопределяя нетрадиционные подходы к оценке её моделей, процессу реализации и субъектам. В первую очередь это обусловлено новыми качествами среды, в которых происходит виктимизация. Её отличают:

- деперсонализация и депсихологизация криминально-виктимного взаимодействия;

- вероятность осуществления, не предопределённая антропологическим статусом (виктимностью могут обладать коллективные социальные субъекты, технически сложные и самоорганизующиеся системы, вычислительные машины и проч.);

- ранее не фиксируемые формы реализации, связанные с автоматизацией процессов виктимизации и рекрутинга потерпевших, использованием системных решений при воздействии на жертв и т.д.;

- ранее не регистрируемые масштабы. Число пострадавших от целевых атак уже достигает десятков миллионов человек за один эпизод (напр., хищение конфиденциальных данных компании Sony с семьюдесятью семью миллионами пострадавших). Высокий уровень виктимизации населения определяет негативные тенденции в обеспечении личной безопасности граждан, а также в социальноэкономическом развитии общества в целом [6].

Виктимизация в интернет-среде вносит ценные поправки в традиционные представления об акте реализации виктимного потенциала. Она существенно дополняет сегмент классической виктимологии и является предметом дальнейшей научной дискуссии.

\section{Список литературы}

1. Актуальные киберугрозы: итоги 2019 года. - URL: https:/www.ptsecurit y.com/ruru/research/analytics/cybersecurity-threatscape-2019/ (дата обращения: 18.01.2021).

2. Андронникова, О. О. Модели девиктимизации человека с ролевой позицией жертвы в социокультурном пространстве // Современные проблемы науки и образования. - 2015. - № 1-2. - С. 216.

3. Ахмедшин, Р. Л. Юридическая психология : курс лекций / Р. Л. Ахмедшин ; М-во образования и науки Российской Федерации ; Томский гос. ун-т систем упр. и радиоэлектроники, фак. дистанционного обучения. - Томск : Эль Контент, 2011. - 226 с.

4. Воронин, Ю. А. Виктимная безопасность: терминологическая интерпретация / Ю. А. Воронин, А. В. Майоров // Криминологический журнал Байкальского государственного университета экономики и права. - 2014. - № 1 (27). - С. 43-48.

5. Герасюкова М. Требовала выкуп, плевала кипятком: эксперт взломал кофемашину // Новая газета. - URL: https:/www.gazeta.ru/tech/2020/09/28/1327 1413/h ack_coffee_machine.shtml (дата обращения: 22.02.2021).

6. Защищенность граждан от преступных посягательств в современной России: основные тенденции и детерминанты / Е. В. Фролова, Н. В. Медведева, Л. В. Сеничева, В. В. Бондалетов. - DOI: 10.17150/1996-7756.2015.9(3).525-537 // Криминоло- 
гический журнал Байкальского государственного университета экономики и права. - 2015. - Т. 9, № 3. - С. 525-537.

7. Как заплатить за одного клиента 3 раза и даже не знать об этом: Практический кейс «Аудиомании». - URL: https:/habr.com/ru/company/audi omania/blog/370 097/ (дата обращения: 11.03.2021).

8. Комаров, А. А. Исследование виктимологических рисков интернетмошенничества в зависимости от возраста пользователей Глобальной сети // Криминологический журнал Байкальского государственного университета экономики и права. - 2012. - № 1. - С. 65-68.

9. Обзор Линукс (Linux) - просто о сложном. - URL: https://1linux.ru/info/obzoros-linux.html (дата обращения: 20.03.2021).

10. Плешаков, В. А. «Форс-мажорная киберпедагогика», или Чрезвычайные условия образования эпохи COVID-19 / В. А. Плешаков, Т. В. Склярова // Homo Cyberus : электронный научно-публицистический журнал. - 2020. - № 1 (8). - URL: http:/journal.hom cyberus.ru/Pleshakov_VA_Sklyarova_TV_1_2020 (дата обращения: 20.03.2021).

11. Социально-психологические особенности студентов, склонных к виктимному поведению в интернет-пространстве / А. Ф. Дроздикова-Зарипова, Н. Н. Калацкая, Р. А. Валеева, Н. Ю. Костюнина, Г. Ф. Биктагирова // Современные наукоемкие технологии. - 2019. - № 12-1. - С. 159-166.

12. Microsoft: в 2019 году 79\% россиян стали жертвами угроз в интернете. URL: https://takiedela.ru/news/2020/02/11/ugrozy-v-internete-2019/ (дата обращения: 17.01.2021).

\section{References}

1. Actual cyber threats: results of 2019. Available at: https://www.ptsecurity.com/ru$\mathrm{ru} /$ research/analytics/cybersecurity-threatscape-2019/(accessed 18 January 2021).

2. Andronnikova O. O. Modeli deviktimizatsii cheloveka s rolevoi pozitsiei zhertvy $\mathrm{v}$ sotsiokul'turnom prostranstve [Models of human devictimization with the role position of the victim in the socio-cultural space]. Sovremennye problemy nauki i obrazovaniya, 2015, no. 1-2, pp. 216.

3. Akhmedshin R. L. Yuridicheskaya psikhologiya: kurs lektsii [Legal psychology: a course of lectures]. Tomsk: El Content Publ., 2011. 226 p.

4. Voronin Yu. A., Mayorov A. V. Viktimnaya bezopasnost': terminologicheskaya interpretatsiya [Victim security: terminological interpretation. Kriminologicheskii zhurnal Baikal'skogo gosudarstvennogo universiteta ekonomiki i prava, 2014, no. 1 (27), pp. 43-48.

5. Gerasyukova M. Trebovala vykup, plevala kipyatkom: ekspert vzlomal kofemashinu [She demanded a ransom, spat boiling water: an expert broke into a coffee machine]. Novaya Gazeta. Available at: https://www.gazeta.ru/tech/2020/09/28/1327 1413/hack_coffee_machine.shtml (accessed 22 February 2021). 
6. Frolova E. V., Medvedeva N. V., Senicheva L. V., Bondaletov. V. V. Zashhishhennost' grazhdan ot prestupnyh posjagatel'stv $v$ sovremennoj Rossii: osnovnye tendencii $i$ determinanty [Protection of citizens from criminal encroachments in modern Russia: main trends and determinants]. Kriminologicheskii zhurnal Baikal'skogo gosudarstvennogo universiteta ekonomiki i prava, 2015, vol. 9, no. 3, pp. 525-537. DOI: 10.17150/1996-7756.2015.9(3).525-537.

7. How to pay for one client 3 times and not even know about it: Practical case "Audiomania". Available at: https://habr.com/ru/company/audiomania/blog/370097/ (accessed 11 March 2021). (In Rissian).

8. Komarov A. A. Issledovanie viktimologicheskih riskov internet-moshennichestva v zavisimosti ot vozrasta pol'zovatelej Global'noj seti [Research of victimological risks of Internet fraud depending on the age of users of the Global Network]. Kriminologicheskij zhurnal Bajkal'skogo gosudarstvennogo universiteta jekonomiki i prava, 2012, no. 1, pp. 65-68.

9 Linux Review - just about the complex. Available at: https://1linux.ru/info/obzoros-linux.html (accessed 20.03.2021). (In Russian).

10. Pleshakov V. A., Slyarova T. V. «Fors-mazhornaja kiberpedagogika», ili Chrezvychajnye uslovija obrazovanija jepohi COVID-19 ["Force majeure cyber pedagogy", or Extraordinary conditions for the formation of the era of COVID-19]. Homo Cyberus, 2020, no. 1 (8). Available at: http://journal.homocyberus.ru/Pleshak ov_VA_Sklyarova_TV_1_2020 (accessed 20.03.2021).

11. Drozdikova-Zaripova A. F., Kalatskaya N. N., Valeeva R. A., Kostyunina N. Yu., Biktagirova G. F. Social'no-psihologicheskie osobennosti studentov, sklonnyh k viktimnomu povedeniju $\mathrm{v}$ internet-prostranstve [Socio-psychological characteristics of students prone to victim behavior in the Internet space]. Sovremennye naukoemkie tehnologii, 2019, no. 12-1, pp. 159-166.

12. Microsoft: in 2019, 79\% of Russians fell victim to online threats. Available at: https://takiedela.ru/news/2020/02/11/ugrozy-v-internete-2019/ (accessed 17 January 2021). 